\title{
Article \\ Climate Justice in an Intergenerational Sustainability Framework: A Stochastic OLG Model
}

\author{
Gianluigi Cisco $^{1}$ (D) and Andrea Gatto ${ }^{2,3,4, *(\mathbb{D})}$ \\ 1 Department of Economic and Legal Studies, University of Naples "Parthenope", 80132 Naples, Italy; \\ gianluigi.cisco@uniparthenope.it \\ 2 Natural Resources Institute, Livelihoods \& Institutions Department, University of Greenwich, \\ Central Avenue, Chatham Maritime ME4 4TB, UK \\ 3 Centre for Studies on European Economy (AIM), Azerbaijan State University of Economics (UNEC), \\ Baku AZ1001, Azerbaijan \\ 4 CED—Center for Economic Development and Social Change, Via Guido De Ruggiero, 80128 Napoli, Italy \\ * Correspondence: a.gatto@greenwich.ac.uk
}

Citation: Cisco, Gianluigi, and Andrea Gatto. 2021. Climate Justice in an Intergenerational Sustainability Framework: A Stochastic OLG Model Economies 9: 47. https://doi.org/ 10.3390/economies 9020047

Academic Editor: George Halkos

Received: 16 January 2021

Accepted: 26 February 2021

Published: 1 April 2021

Publisher's Note: MDPI stays neutral with regard to jurisdictional claims in published maps and institutional affiliations.

Copyright: (c) 2021 by the authors. Licensee MDPI, Basel, Switzerland. This article is an open access article distributed under the terms and conditions of the Creative Commons Attribution (CC BY) license (https:/ / creativecommons.org/licenses/by/ $4.0 /)$.
Abstract: Climate justice is conceived as the intertemporal climate equity and equality exchange amongst generations. Sustainability -intended as the interplay amongst the economy, the society, the environment, and the governance-is essential to forge the climate justice theoretical framework. On this base, the study attempts to model the intertemporal choice of the status quo amongst generations in these four domains, making use of an overlapping generations (OLG) model making use of an intertemporal choice framework. The proxies detected are GDP growth (economy), environmental quality (environment), and labor growth, and environmental investment (society) as assumptions. The governance dimension is captured by the difference in wealth between young and old generations. The work aims at replying to the following research question: Which are the conditions for sustainable development such that climate justice holds? The intra-intergenerational exchange is defined in two periods, while the individual provides their preferred economic and environmental choice mix as consumption-saving. This study shows that keeping the business-as-usual scenario, young generations will have to bear the brunt of sustainable development. Additionally, reduced emissions are only achievable with increased efforts by the youth by reducing their leisure and consumption. These facts call for enhanced intergenerational sustainability and climate justice policies.

Keywords: overlapping generations; climate justice; technology shock; environmental quality; OLG model; intergenerational sustainability; commons; resource governance

\section{Introduction}

Climate justice is nowadays an ecological and societal conundrum having major implications on public health (Introcaso 2018). Climate justice calls for urgent governance actions targeting climate change adaptation (Sovacool 2013). The issue became paramount in the international forums with the COP21 and major climate change and environmental protection summits (Gatto 2020; IPCC 2018; Rhodes 2016), and got popularity after a series of climate strikes, climate activism, and civil society unrest-whereby Greta Thunberg became the most renowned representative of a primarily youth-driven movement (Rutter 2019). Climate justice is closely connected with energy and resource justice, sustainable development, and the common pools resources theory (Jenkins 2018; Bickerstaff et al. 2013). Climate justice calls for vulnerability protection (Shue 2014), where resilience actions to tackle resources sustainability are detected as priorities (Agovino et al. 2018).

In this sense, climate justice firstly calls for energy resilience strategies and policies to face vulnerability and empower the vulnerable (Gatto and Busato 2020; Gatto and Drago 2020a, 2020b). Climate justice is an interdisciplinary issue, to be tackled with a multidimensional approach (Roser et al. 2015). Climate justice reckons on climate changeand its mitigation and protection. Climate justice has been conceived in different ways by 
previous scholarship. In terms of resource governance, it has been catalogued as either a global public good or a commons due to its intergenerational attributes and the conflicts affecting the different cohorts-being either rival or nonrival in its use (Ostrom 2015; Shaffer 2012; Ostrom 2010; Nordhaus 2006; Grasso 2004; Kaul et al. 2003; Kelleher 2000; Nordhaus 1994). However, it shall be noticed that the two goods categories are often confused or even interpreted as synonyms (Brando et al. 2019). For this reason, climate needs tailored governance and policy actions to achieve its most effective use and benefit.

Climate vulnerability and resilience are hot button topics in the international development agenda. This is particularly relevant for issues related to natural resources management, the energy-food-water nexus and overall climate change (Campbell et al. 2018; Agovino et al. 2018). In 2015, the Sustainable Development Goals (SDGs) have settled 17 goals and 169 targets to tackle poverty and achieve sustainable development in OECD and least developed countries (United Nations (UN) 2015). In this framework, the need for promoting climate resilience policies to face climate change vulnerability issues plays a crucial role (Brenkert and Malone 2005). The world has become more vulnerable to a series of shocks and adverse events, especially regarding natural hazards. These stylized facts concerning climate change vulnerability affect often the most vulnerable categories, countries and minorities e.g., people with disabilities, refugees and migrants, poor, women, youth, and rural people (Agovino et al. 2018; Gatto et al. 2016; Picot and Moss 2014).

To the best knowledge of this research's authors, no scholarship modeling climate justice has been published so far yielding a clear potential for research novelty. Nevertheless, the literature on climate change modeling is broad. Weitzman (2009) analyzed the economic implications of climate change calamities. Sen (2008) stressed the importance of renewable energy and the atmosphere for climate change. The concept of climate as a commons was modeled by Nordhaus (1994). Brenkert and Malone (2005) emphasized the role of vulnerability and resilience to climate change. Martens (2013) connected climate change with health studies, examining the effects of ozone depletion and global warming. $\mathrm{Xu}$ (2000) studied the effects of climate change on water governance. Koca et al. (2006), examined natural ecosystems impact, focusing on Sweden.

At the same time, the authors are not aware of further applications of OLG models to climate justice. OLG models have been utilized for disentangling climate-economy interactions by Howarth (1998). Stephan et al. (1997) modeled infinitely lived agents as for the economics of global warming. Sachs (2014) oriented a climate change OLG model on global warming and intergenerational wellbeing. Schneider et al. (2012) focused on the trade-offs amongst generations in a continuous-time. John and Pecchenino (1994) were most concerned about the existing connections between growth and the environment. Bayer and Cansier (1996) scrutinized the issue through the lens of systematic intergenerational discounting. Gerlagh and Keyzer (2001) developed an OLG model to draw a scenario analysis based on possible resource management and intertemporal environmental choices rendering diverse policy outcomes.

This work assumes climate justice coming from the intergenerational climate equity and equality, being deliverable solely through an ethical, sustainable approach (Stern and Taylor 2007; Francis 2015; McKinnon 2015; UNESCO 2014). In this regard, sustainability requires the simultaneous combination of a balanced economic, social, environmental, and governance mix. Holding these conceptual premises, the study attempts to contribute to the existing theoretical literature on climate justice, offering a model to theorize the intertemporal choice amongst generations in these four domains. For such scope, it is exploited an overlapping generations (OLG) model. Thus, it is proposed as a research question: Which are the conditions for sustainable development such that climate justice holds? The study has previously explored the phenomenon of climate justice and interconnected vulnerability and resilience issues, drafting a review on climate change modeling. The paper's remainder is as follows: Section 2 presents the OLG model developed in this study, focusing on the welfare measure and competitive equilibrium. Thus, Section 3 provides the calibration and steady-state conditions, whereas Section 4 , investigates the impulse re- 
sponse analysis. Therefore, Section 5 drafts the works conclusions and policy implications, sketching the paper's limitations and future research.

\section{The Model}

This section shows the main features of the OLG modeling. This work is based on intertemporal choice theory-hence, it relies on rational expectations. The aim is to sketch the status quo of climate justice and intertemporal sustainability to better depict the two phenomena and their interplay. In terms of modeling, the paper paves the way for comparisons between classic OLGs and OLGs complemented with the environment-that is already quite an innovative item. As in the standard Diamond (1965) OLG model, this study considers an overlapping generations model in which each consumer lives two periods: young and old.

\subsection{Consumers}

In each period $t>0$, a new generation of identical consumers is born. The size of generation $t$ is given by $N_{t}=(1+n)^{t}$, with $n>0$. All consumers have one unit of time endowment, which can be allocated between work and leisure. Retirement is obligatory in the second period of life, so the labor supply of old consumers is zero. Consumers-both young and old-benefit from environmental quality. The latter is not considered a control variable-it is indirectly improved through investments that produce beneficial effects only after a period of time. Consider a consumer who is born at time $t \geq 0$. Let $c_{y, t}$ and $c_{0, t+1}$ denote his consumption when young and old, respectively, $l_{t}$ denote his labor supply when young, and $Q_{t}$ is the environmental quality index. The consumers' preferences are represented by:

$$
\begin{gathered}
U_{t}\left(c_{y, t}, l_{t}, Q_{t}, c_{o, t+1}, Q_{t+1}\right)=\frac{c_{y, t}^{1-\sigma}}{1-\sigma}+A \frac{Q_{t}^{1-\sigma_{e}}}{1-\sigma_{e}}-B \frac{l_{t}^{1+\psi}}{1+\psi}+\beta\left(\frac{c_{o, t+1} 1^{1-\sigma}}{1-\sigma}+A \frac{Q_{t+1}^{1-\sigma_{e}}}{1-\sigma_{e}}\right), \quad \sigma_{i} \neq 1 \\
U_{t}\left(c_{y, t}, l_{t}, Q_{t}, c_{o, t+1}, Q_{t+1}\right)=\ln \left(c_{y, t}\right)+A \ln \left(Q_{t}\right)-B \frac{l_{t}^{1+\psi}}{1+\psi}+\beta\left[\ln \left(c_{o, t+1}\right)+A \ln \left(Q_{t+1}\right)\right], \quad \sigma_{i}=1
\end{gathered}
$$

where $\sigma>0$ and $\sigma_{e}>0$ are measures of risk aversion, $\psi>0$ is the inverse of the Frisch elasticity of labor supply, $\beta \in(0,1)$ is the subjective discount factor, $\mathrm{A}$ and $\mathrm{B}$ are positive constant parameters representing the weight given to environmental quality relative to private consumption and the weight given to work's disutility, respectively. The environmental quality at time $t+1$ (measured by the environmental index $Q$ ) is degraded by consumption of the old at time $t$ and improved by environmental investments, $m_{t}$. As in John and Pecchenino (1994) and Angelopoulos et al. (2010, 2013), we assume the following functional form:

$$
Q_{t+1}=\left(1-\delta_{q}\right) \bar{Q}+\delta_{q} Q_{t}-P_{t}+\phi m_{t}
$$

where $\bar{Q}$ represents environmental quality without pollution, $P_{t}$ is the current pollution flow, $m_{t}$ is private spending on abatement activities, $\phi$ is the environmental spending converter, and $\delta_{q} \in(0,1)$ is parameters measuring the degree of environmental persistence and defines how private investments convert into an improvement of the environmental quality index. In detail, pollution is proportional to output:

$$
P_{t}=\gamma y_{t}
$$

where $\gamma>0$ denote the emissions intensity.

Therefore, the consumer can save on two types of assets: physical capital and an environmental worthless asset. Taking $\left\{w_{t}, R_{t+1}\right\}$ as given, the consumers' problem is to choose an allocation $\left\{c_{y, t}, l_{t}, c_{o, t+1}, s_{t}, m_{t}\right\}$ so as to maximize his lifetime utility in (1) or (2), subject to the following budget constraints:

$$
c_{y, t}+m_{t}+s_{t}=w_{t} l_{t}
$$




$$
c_{0, t+1}=s_{t} R_{t+1}
$$

The Lagrangian function associated with this problem is the following:

$$
\max _{\left\{c_{y, t}, l_{t}, c_{o, t+1}, s_{t}, m_{t}\right\}} \mathcal{L}_{t}=U_{t}\left(c_{y, t}, l_{t}, Q_{t}, c_{o, t+1}, Q_{t+1}\right)+\lambda_{t}\left(w_{t} l_{t}-c_{y, t}-m_{t}-s_{t}\right)
$$

The first-order conditions for this maximization problem are the following:

$$
\begin{gathered}
\frac{\partial \mathcal{L}_{t}}{\partial c_{y, t}}=c_{y, t}-\sigma-\lambda_{t}=0 \\
\frac{\partial \mathcal{L}_{t}}{\partial c_{o, t+1}}=\beta c_{o, t+1}{ }^{-\sigma}-\frac{\lambda_{t}}{R_{t+1}}=0 \\
\frac{\partial \mathcal{L}_{t}}{\partial l_{t}}=w_{t} \lambda_{t}-B l_{t}^{\psi}=0 \\
\frac{\partial \mathcal{L}_{t}}{\partial m_{t}}=\beta A Q_{t+1}^{\sigma_{e}} \phi-\lambda_{t}=0
\end{gathered}
$$

Using these equations, we obtain:

$$
c_{y, t}=\frac{c_{o, t+1}}{\left(\beta R_{t+1}\right)^{\frac{1}{\sigma}}}=\left(\frac{B l_{t}^{\psi}}{w_{t}}\right)^{-\frac{1}{\sigma}}=\left(\beta A Q_{t+1}^{\sigma_{e}} \phi\right)^{-\frac{1}{\sigma}}
$$

Manipulating Equations (11) and (5) we also obtain the following relationships:

$$
\begin{gathered}
c_{y, t}=\frac{w_{t} l_{t}}{1+\beta^{\frac{1}{\sigma}} R_{t+1}^{\frac{1}{\sigma}-1}} \\
s_{t}+m_{t}=\Gamma\left(R_{t+1}\right) w_{t} l_{t}, \Gamma\left(R_{t+1}\right)=\frac{\beta^{\frac{1}{\sigma}} R_{t+1}^{\frac{1}{\sigma}-1}}{1+\beta^{\frac{1}{\sigma}} R_{t+1}^{\frac{1}{\sigma}-1}}
\end{gathered}
$$

An increase in $R_{t+1}$ has two opposing effects on saving which are captured by the function $\Gamma\left(R_{t+1}\right)$. First, the consumer will receive more interest income when he is old-this determining an income effect that encourages consumption when young and discouraging saving. Second, an increase in interest rate also lowers the relative price of future consumption. This creates an intertemporal substitution effect that discourages consumption when young and promotes saving. The strength of the two effects depends on the value of $\sigma$. In particular, the intertemporal substitution effect dominates when $\sigma<1$, and $\sigma>1$, the income effect dominates. The two effects exactly cancel out when $\sigma=1$. Moreover, from Equation (11) we notice the importance of risk aversion parameters. In the case of $\sigma<\sigma_{e}$, agents are more sensitive to environmental risk than the risk regarding investments.

\subsection{Firms}

On the supply side of the economy, there is a large number of identical firms. In each period, each firm hires labor $\left(l_{t}\right)$ and physical capital $\left(k_{t}\right)$ from the competitive factor markets, and produces output according to:

$$
y_{t}=A_{t} k_{t}^{\alpha} l_{t}^{1-\alpha}
$$

From the profit maximization, we obtain the following first-order conditions (see Appendix A for further details.):

$$
\begin{gathered}
R_{t}=\alpha A_{t} k_{t}^{\alpha-1} l_{t}^{1-\alpha} \\
w_{t}=(1-\alpha) A_{t} k_{t}^{\alpha} l_{t}^{-\alpha}
\end{gathered}
$$


where $A_{t}$ represents the total factor productivity (TFP). As in most dynamic stochastic general equilibrium (DSGE) models (e.g., Kydland and Prescott 1982; Smets and Wouters 2007; Chang and Kim 2007), TFP follows a first-order autoregressive process with an i.i.d.-normal error term $(\mathrm{AR}(1))$ :

$$
\ln \left(A_{t}\right)=\rho \ln \left(A_{t-1}\right)+\epsilon_{t}
$$

where $0<\rho<1$ is the shock persistence and $\epsilon_{t}$ is the error term with mean zero and standard deviation $\sigma_{a}>0$.

\subsection{Welfare Measures}

To assess the implications on welfare, as in Mendicino and Pescatori (2007), the current welfare is measured by the discounted utility function of the young and old agents:

$$
\begin{aligned}
& W_{y, t}=\mathbb{E}_{t} \sum_{t=0}^{\infty} \beta^{t} U_{y, t} \\
& W_{o, t}=\mathbb{E}_{t} \sum_{t=0}^{\infty} \beta^{t} U_{o, t}
\end{aligned}
$$

\subsection{Competitive Equilibrium}

The decentralized competitive equilibrium for a given process followed by technology the initial values for the capital stock, the environmental quality and pollution is a list of sequences $\left\{c_{y, t}, c_{0, t+1} l_{t}, Q_{t}, m_{t}\right\}_{t=0}^{\infty}$, and prices $\left\{w_{t}, R_{t}\right\}_{t=0}^{\infty}$ such that the markets are clear, consumers maximize their utility function subject to their budget constraints, firms maximize the profit and the environmental quality follow their law of motion. From the competitive equilibrium, it is obtained the following law of motion:

$$
(1-n) k_{t}+1=s_{t}=(1-\alpha)\left[\frac{\beta^{\frac{1}{\sigma}} R_{t+1}^{\frac{1}{\sigma}-1}}{1+\beta^{\frac{1}{\sigma}} R_{t+1}^{\frac{1}{\sigma}-1}}\right]\left(\frac{k_{t}}{l_{t}}\right)^{-\alpha} l_{t}-m_{t}
$$

If the investment in pollution reduction is positive, all other things being equal, the capital (savings) decrease. Adjusting the hours worked can enable sustainable development.

\section{Calibration}

This section presents model calibration between parameters drawn from typical macroeconomic literature and environmental parameters extracted from selected studies on emission and global temperature dynamics.

The economic parameters' values are calibrated for the US economy as in most overlapping generation models studies, and time is measured in quarters. Thus, the baseline values used for the rate of time preference-the depreciation rate of capital, the capital share in output, the inverse of Frisch elasticity, and the persistence parameter of the technology process-are the standards used in this literature (e.g., Shi and Suen 2014). Parameters A and $\mathrm{B}$ are calibrated endogenously, whereas parameters characterizing the environmental sector are in line with John and Pecchenino (1994), Angelopoulos et al. (2010; 2013), and Annicchiarico and Di Dio (2015). Table 1 lists the parameters used in the baseline model.

Following Schechter (2007), two calibrations for the risk aversion parameter are provided. First, this manuscript considers the case of $\sigma$ equal to one. Second, to evaluate some effects related to the income effects, this study adopts $\sigma=2$. Although these latter represent standard parametrization in OLG literature, this work provides an additional simulation to examine the implication for climate justice robustly. In this simulation, the risk aversion parameter is lower than one and is lower than the environmental risk aversion parameter. 
Table 1. Model Calibration.

\begin{tabular}{crc}
\hline Parameter & Description & Value \\
\hline$\beta$ & Discount factor & 0.99 \\
$\delta$ & Depreciation rate capital & 0.025 \\
$\sigma$ & Risk aversion parameter & $1-2-0.75$ \\
$\sigma_{e}$ & Risk aversion parameter environment & $1-2$ \\
$\psi$ & Inverse of Frisch elasticity & 1 \\
$\alpha$ & Share of capital & 0.30 \\
$\gamma$ & Pollution intensity & 0.38 \\
$\delta_{q}$ & Degree of environmental persistence & 0.90 \\
$\phi$ & Environmental investment converter & 1 \\
$\bar{Q}$ & Environmental quality without pollution & 1 \\
$\rho$ & Persistence of the technology shock & 0.90 \\
\hline$A$ & Long-run total factor productivity & 1 \\
\hline
\end{tabular}

\section{Steady-State}

This section shows the stationary equilibrium of the economy with and without private investment in pollution abatement. First, it is characterized by the stationary equilibrium of an economy with zero environmental investment, i.e., $m=0$ for all $t \geq 0$. A stationary equilibrium is a competitive equilibrium in which $k_{t}=k^{*}, l_{t}=l^{*}$ and $R_{t}=R^{*}$ for all $t \geq 0$. Substituting these conditions into Equation (20) gives:

$$
\left[\frac{\beta^{\frac{1}{\sigma}} R^{* \frac{1}{\sigma}-1}}{1+\beta^{\frac{1}{\sigma}} R^{* \frac{1}{\sigma}-1}}\right]\left(\frac{k^{*}}{l^{*}}\right)^{-\alpha}=\frac{1+n}{1-\alpha}
$$

Manipulating Equation (21) we obtain:

$$
\Theta\left(R^{*}\right)=\left[\frac{\beta^{\frac{1}{\sigma}} R^{* \frac{1}{\sigma}}}{1+\beta^{\frac{1}{\sigma}} R^{* \frac{1}{\sigma}-1}}\right]=\frac{\alpha(1+n)}{1-\alpha}
$$

Equation (20) follows from the fact that $R_{t}=\alpha\left(\frac{k^{*}}{l^{*}}\right)^{\alpha-1}$. For $\sigma>0, \quad \Theta\left(R^{*}\right)$ is strictly increasing with: $\lim _{R^{*} \rightarrow 0}\left(R^{*}\right)=0$ and $\lim _{R^{*} \rightarrow \infty} \Theta\left(R^{*}\right)=\infty$. Hence exists a unique $R^{*}>0$ that solves Equation (21). The steady-state value of all other variables can be uniquely determined by:

$$
\begin{gathered}
w^{*}=(1-\alpha)\left(\frac{\alpha}{R^{*}}\right)^{\frac{\alpha}{1-\alpha}} \\
l^{*}=B^{-\frac{1}{\alpha+\psi}}\left[\left(1+\beta^{\frac{1}{\sigma}}\left(R^{*}\right)^{\frac{1}{\sigma}-1}\right)\right]^{\frac{\sigma}{\sigma+\psi}}\left(w^{*}\right)^{\frac{1-\sigma}{\sigma+\psi}} \\
k^{*}=l^{*}\left(\frac{\alpha}{R^{*}}\right)^{\frac{1}{1-\alpha}} \\
y^{*}=\left(k^{*}\right)^{\alpha}\left(l^{*}\right)^{1-\alpha} \\
c_{y}^{*}=\frac{c_{0}^{*}}{\left(\beta R^{*}\right)^{\frac{1}{\sigma}}} \\
P^{*}=\gamma y^{*} \\
Q^{*}=\bar{Q}-\frac{P^{*}}{\left(1-\delta_{q}\right)}
\end{gathered}
$$

Conversely, in the case of environmental investment, the stationary equilibrium starts from the following steady-state condition: 


$$
m^{*}+(1-n) k^{*}+1=m^{*}+s^{*}=(1-\alpha)\left[\frac{\beta^{\frac{1}{\sigma}} R^{* \frac{1}{\sigma}}}{1+\beta^{\frac{1}{\sigma}} R^{*^{\frac{1}{\sigma}}-1}}\right]\left(\frac{k^{*}}{l^{*}}\right)^{-\alpha}
$$

Then substituting $R^{*}$ into Equations (23)-(27) yields a unique set of steady-state values for the scenario in which consumers use part of their pollution abatement resources.

In order to determine the steady-state values, the necessity of a specific numerical example arose. The software Dynare was employed to obtain a solution for the equilibrium employing a nonlinear Newton-type solver. ${ }^{1}$ Table 2 reports the deterministic steady-state for variables chosen to understand the climate justice behavior in accord with the discussed calibration and considering different value for the risk aversion parameter $\sigma$. In detail, the proxies detected are (i) output for the economic growth; (ii) environmental quality to define the status of the environment; (iii) labor and environmental investment to determine the level of society; (iv) welfare from young and old to detect the intergenerational inequalities. The other variables are useful to understand the mechanisms inside the depicted model economy.

Table 2. Numerical example-steady-state.

\begin{tabular}{ccccc}
\hline Variables & OLG & OLG-Q & OLG-Q & OLG-Q \\
\hline & $\boldsymbol{\sigma = 1}$ & $\boldsymbol{\sigma}=\mathbf{1}$ & $\boldsymbol{\sigma}=\mathbf{2}$ & $\sigma=\mathbf{0 . 7}$ \\
\hline Interest Rate & 1.492 & 1.915 & 2.352 & 1.661 \\
Output & 0.166 & 0.191 & 0.170 & 0.192 \\
Capital-Saves & 0.034 & 0.030 & 0.022 & 0.034 \\
Labor & 0.331 & 0.424 & 0.422 & 0.401 \\
Abatement Spending & 0.000 & 0.029 & 0.027 & 0.023 \\
Environmental Quality & 0.000 & 0.033 & 0.033 & 0.027 \\
Pollution & 0.017 & 0.019 & 0.017 & 0.019 \\
Welfare-Young & -4.631 & -7.633 & -64.524 & 1.164 \\
Welfare-Old & -2.521 & -4.743 & -21.613 & 2.083 \\
\hline
\end{tabular}

The first column shows the value in the standard Diamond OLG model. In this case, $m=0$, and the environmental quality index is equal to zero. In this context, climate justice does not hold, seeing as how the agents maximize their welfare, ignoring the impact on the environment of their actions. In contrast, in the case of $m>0$, young generations employ parts of their resources to invest in improving environmental quality. In the model described in this work, a sustainable development hypothesis holds if $\mathrm{R}$ and labor are higher than the case without environmental investment. When $\sigma$ is equal to 1 , both the environmental quality index and pollution increase, but this is obtained through increased labor from the young. Hence, improving environmental quality has a more significant impact on young people. The impact becomes even more important if $\sigma=2$. Thus, there is a reduction in intragenerational justice. By contrast, in a low-risk aversion scenario, an environmental and socially sustainable development profile can be reached. A high level of output can be achieved by improving the environmental quality and reducing the generation inequalities. In this context, the environmental risk aversion prevails over economic risk aversion $\left(\sigma<\sigma_{e}\right)$. These characteristics allow agents to make beneficial choices for the environment with less effort from the younger generations.

\section{Impulse Response Analysis}

This section provides the impulse response analysis of a technology shock. In detail, in order to verify the impact of the shock on the climate justice variables, we provide a comparison of our model with the classical Diamond model in the case of $\sigma=1$. Figure 1 shows the impulse response functions after a positive productivity shock of

1 We use Dynare software (available on https:/ /www.dynare.org/, accessed on 1 August 2019) and function Fsolve under MATLAB to determine the steady-state values (for further details see Adjemian et al. 2011). 
$1 \%$. This simulation allows understanding climate justice related to the business cycle fluctuations in two scenarios: environmentally "indifferent" and "aware" consumers. The simulations were obtained using numerical analysis and perturbation methods to simulate the economy and compute the equilibrium conditions outside the steady-state. We solved the model using a second-order Taylor approximation around its steady-state (see (Judd 1998) and (Schmitt-Grohe and Uribe 2004)).
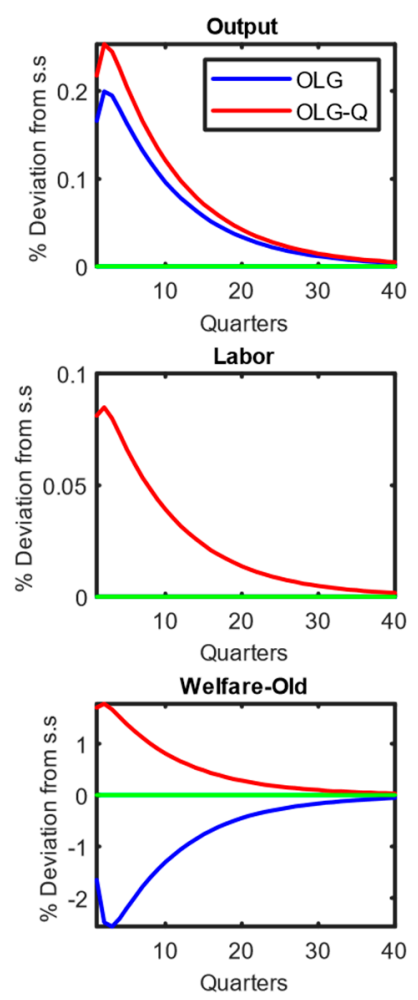

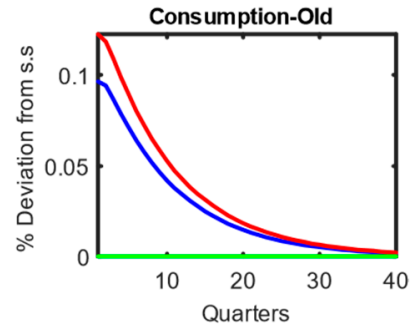

Welfare-Young
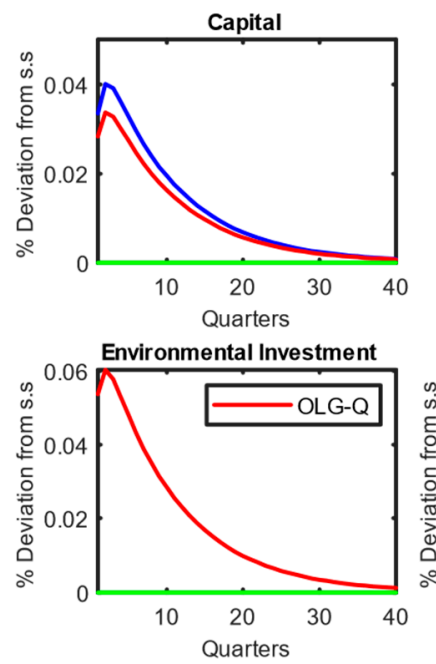

Figure 1. Impulse response to a technology shock (1\%).

All results are reported as percentage deviations from the steady-state. As shown in Figure 1, the productivity shock determines the growth of the output in both cases. The model with environmental investments allows reaching a greater output peak, triggered by a rise in labor from the young generation. Instead, the hours worked do not undergo a significant change in the classical model, and the environmental investments are equal to zero. Both young and old consumption increase after a technology shock. The young generations perform less increase in the Diamond model augment with environmental investment since they use a part of their income to improve environmental quality. By contrast, the old generation can consume a greater quantity if the younger generations invest in improving environmental quality. The standard OLG model does not allow sustainable development. However, the OLG model with environmental investments allows for sustainable development and improvement of environmental quality. The commitment of young people to reduce pollution allows the growth of the well-being of both generations.

\section{Conclusions and Policy Implications}

The stylized facts synthesized draw a world where economic growth needs and prosperity for all have to be coupled with sustainability for the main international community goals. The limits to growth were already flagged in 1972 from the Club of Rome (Meadows et al. 1972), where it was expressed the necessity to foster a long-term, intergenerational, and inclusive development. In this regard, the complex phenomena tackled by sustainable development started requiring a multidimensional approach, that was faced through a number of methodologies, solvable thanks to diverse composite indicator 
techniques inter alia (Nardo et al. 2005; Drago and Gatto 2018). Climate justice relies on practical bottom-up and pushed-down actions fostering the vulnerable empowerment. Major support is being reached by expanding sectors and development programs such as microfinance. Through a set of instruments, as microloans to jumpstart or consolidate micro-entrepreneurship, remittances from workers abroad, microinsurance against shocks, and saving schemes, these programs aim to work for women, youth, rural people, and vulnerable categories empowerment, ensuring climate resilience policies above all connecting them with energy, food and water security, resilience, and justice (Gatto and Busato 2020). These features are recently becoming of great effectiveness whether connected with energy, agriculture, water and resources, passing by entrepreneurship boosting (Gatto and Drago 2021). An example is the implementation of microfinance programs for energy entrepreneurship in sub-Saharan Africa. The understanding of the possible generation interplays will have foremost importance in preserving good environmental quality. Attributing a sound role to policy and politics in nudging the socioeconomic and ecological concerns will be decisive for addressing upcoming directions of climate justice and is multilayered and polycentric. Foreseeable actions rely on international, domestic and local governance that will be able to shape the future of human, ecosystems and planetary health (Panarello 2021; Punzo et al. 2019; Held and Roger 2018; Ostrom 2012). Crucial measures will have to be detected from environmental responsibility and behaviors, international environmental agreements and protocols, and energy and resource transition (Sadik-Zada and Gatto 2020; 2021).

In this paper, it was shown that when $R(m)>R$, labor supply is elastic and consumers are less risk-averse, and possibly reaches a stationary state in which climate justice holds. Besides, this study shows that the business-as-usual climate justice is currently achievable only with an increase in young effort and with a reduction in their leisure and consumption - that is a sustainability paradox. Achieving an improved balance is linked to consumer culture: they want a smoothed consumption prole over time, reducing its variability. The households' risk aversion makes it harder to achieve the desirable stationary equilibrium. The model displays potential for further implementations. One direction for future research is to extend these results to a Ramsey Model in order to analyze the optimal taxation. Another possibility is to extend the model to allow an intergenerational analysis considering several cohorts. Further developments to this exercise would include making use of alternative baseline economies - other than the US yardstick calibration. Other papers could consider policy effects as carbon taxes or caps on trade as sensitivity analysis or alternative models and scenarios.

Author Contributions: All authors contributed equally to the work. All authors have read and agreed to the published version of the manuscript.

Funding: This research received no external funding.

Acknowledgments: The authors shall acknowledge Reyer Gerlagh for his insightful comments. The authors are also grateful to Demetrio Panarello, Maria Carratù and all participants of the 4th Conference on "Econometric Models of Climate Change" at the University of Milan-Bicocca (Milan, Italy) on 29-30 August 2019, Center for European Studies (CefES) and the Department of Economics, Management and Statistics (DEMS) at the University of Milan-Bicocca, CREATES at Aarhus University, Department of Economics and Finance (DEF) at the University of Rome-Tor Vergata, Climate Econometrics at the University of Oxford and the Department of Economics at the University of Victoria.

Conflicts of Interest: The authors declare no conflict of interest. 


\section{Appendix A}

In a decentralized economy, the households' objective is to maximize the lifetime welfare by choosing the levels of consumptions $\left(c_{y, t}, c_{0, t+1}\right)$, environmental expenditure $\left(m_{t}\right)$, labor $\left(l_{t}\right)$, and save $\left(s_{t}\right)$, under constraints of resources, pollution and the environmental quality:

$$
\begin{gathered}
\max _{\left\{c_{y, t}, l_{t}, c_{o, t+1}, s_{t}, m_{t}\right\}} U_{t}\left(c_{y, t}, l_{t}, Q_{t}, c_{o, t+1}, Q_{t+1}\right) \\
\text { s.t: }\left\{\begin{array}{c}
Q_{t+1}=\left(1-\delta_{q}\right) \bar{Q}+\delta_{q} Q_{t}-P_{t}+\phi m_{t} \\
c_{y, t}+m_{t}+s_{t}=w_{t} l_{t} \\
c_{o, t+1}=s_{t} R_{t+1}
\end{array}\right.
\end{gathered}
$$

The Lagrangian associated with this problem is the following:

$$
\max _{\left\{c_{y, t}, l_{t}, c_{0, t+1}, s_{t}, m_{t}\right\}} \mathcal{L}_{t}=U_{t}\left(c_{y, t}, l_{t}, Q_{t}, c_{o, t+1}, Q_{t+1}\right)+\lambda_{t}\left(w_{t} l_{t}-c_{y, t}-m_{t}-s_{t}\right)
$$

where:

$$
s_{t}=\frac{c_{o, t+1}}{R_{t+1}}
$$

and:

$$
Q_{t+1}=\left(1-\delta_{q}\right) \bar{Q}+\delta_{q} Q_{t}-P_{t}+\phi m_{t}
$$

The first-order conditions for this maximization problem are the following:

$$
\begin{gathered}
\frac{\partial \mathcal{L}_{t}}{\partial c_{y, t}}=c_{y, t}{ }^{-\sigma}-\lambda_{t}=0 \\
\frac{\partial \mathcal{L}_{t}}{\partial c_{0, t+1}}=\beta c_{o, t+1}{ }^{-\sigma}-\frac{\lambda_{t}}{R_{t+1}}=0 \\
\frac{\partial \mathcal{L}_{t}}{\partial l_{t}}=w_{t} \lambda_{t}-B l_{t}^{\psi}=0 \\
\frac{\partial \mathcal{L}_{t}}{\partial m_{t}}=\beta A Q_{t+1}^{\sigma_{e}} \phi-\lambda_{t}=0
\end{gathered}
$$

The representative firm goal is to maximize its profits under the technology constraint:

$$
\begin{gathered}
\max _{l_{t}, k_{t}} \Pi_{t}=y_{t}-w_{t} l_{t}-R_{t} k_{t} \\
\text { s.t } \\
y_{t}=A_{t} k_{t}^{\alpha} l_{t}^{(1-\alpha)}
\end{gathered}
$$

The first-order conditions for this maximization problem are the following:

$$
\begin{gathered}
\frac{\partial \Pi_{t}}{\partial k_{t}}=\alpha A_{t} k_{t}^{\alpha-1} l_{t}^{(1-\alpha)}-R_{t}=0 \\
\frac{\partial \Pi_{t}}{\partial l_{t}}=(1-\alpha) A_{t} k_{t}^{\alpha} l_{t}^{-\alpha}-w_{t}=0
\end{gathered}
$$

\section{References}

Adjemian, Stephane, Houtan Bastani, Michel Juillard, Frederic Karame, Junior Maih, Ferhat Mihoubi, Willi Mutschler, George Perendia, Johannes Pfeifer, Marco Ratto, and et al. 2011. Dynare: Reference Manual. Paris: Cepremap, version 4.

Agovino, Massimiliano, Massimiliano Cerciello, and Andrea Gatto. 2018. Policy efficiency in the field of food sustainability. The adjusted food agriculture and nutrition index. Journal of Environmental Management 218: 220-233. [CrossRef] [PubMed]

Angelopoulos, Konstantinos, George Economides, and Apostolis Philippopoulos. 2010. What Is the Best Environmental Policy? Taxes, Permits and Rules under Economic and Environmental Uncertainty. Working Papers 119. Athens: Bank of Greece. 
Angelopoulos, Konstantinos, George Economides, and Apostolis Philippopoulos. 2013. First-and second-best allocations under economic and environmental uncertainty. International Tax and Public Finance 20: 360-80. [CrossRef]

Annicchiarico, Barbara, and Fabio Di Dio. 2015. Environmental policy and macroeconomic dynamics in a new Keynesian model. Journal of Environmental Economics and Management 69: 1-21. [CrossRef]

Bayer, Stefan, and Dieter Cansier. 1996. Systematic Discounting in Climate Policy Analysis (No. 85). Tübinger Diskussionsbeiträge: University of Tuebingen.

Bickerstaff, Karen, Gordon Walker, and Harriet Bulkeley, eds. 2013. Energy Justice in a Changing Climate: Social Equity and Low-Carbon Energy. London: Zed Books Ltd.

Brando, Nicolas, Christiaan Boonen, Samuel Cogolati, Rutger Hagen, Nils Vanstappen, and Jan Wouters. 2019. Governing as commons or as global public goods: Two tales of power. International Journal of the Commons 13: 1. [CrossRef]

Brenkert, Antoinette L., and Elizabeth L. Malone. 2005. Modeling vulnerability and resilience to climate change: A case study of India and Indian states. Climatic Change 72: 57102. [CrossRef]

Campbell, Bruce M., James Hansen, Janie Rioux, Clare M. Stirling, and Stephen Twomlow. 2018. Urgent action to combat climate change and its impacts (SDG 13): Transforming agriculture and food systems. Current Opinion in Environmental Sustainability 34: 13-20. [CrossRef]

Chang, Yongsung, and Sun B. Kim. 2007. Heterogeneity and aggregation: Implications for labor-market fluctuations. American Economic Review 97: 1939-56. [CrossRef]

Diamond, Peter. A. 1965. National debt in a neoclassical growth model. The American Economic Review 55: 1126-50.

Drago, Carlo, and Andrea Gatto. 2018. A robust approach to composite indicators exploiting interval data: The interval-valued global gender gap index (IGGGI). In IPAZIA Workshop on Gender Issues. Cham: Springer, pp. 103-14.

Francis, Pope. 2015. On Care for Our Common Home: Laudato si. Available online: https://www.usccb.org/issues-and-action/ human-life-and-dignity/environment/upload/laudato-si-discussion-guide.pdf (accessed on 31 March 2021).

Gatto, Andrea. 2020. A pluralistic approach to economic and business sustainability: A critical meta-synthesis of foundations, metrics, and evidence of human and local development. Corporate Social Responsibility and Environmental Management 27: 1525-39. [CrossRef]

Gatto, Andrea, and Carlo Drago. 2020a. A taxonomy of energy resilience. Energy Policy 136: 111007. [CrossRef]

Gatto, Andrea, and Carlo Drago. 2020b. Measuring and modeling energy resilience. Ecological Economics 172: 106527. [CrossRef]

Gatto, Andrea, and Carlo Drago. 2021. When renewable energy, empowerment, and entrepreneurship connect: Measuring energy policy effectiveness in 230 countries. Energy Research $\mathcal{E}$ Social Science. forthcomting.

Gatto, Andrea, and Francesco Busato. 2020. Energy vulnerability around the world: The global energy vulnerability index (GEVI). Journal of Cleaner Production 253: 118691. [CrossRef]

Gatto, Andrea, Norman Polselli, and Gretchen Bloom. 2016. Empowering gender equality through rural development: Rural markets and micro-finance in Kyrgyzstan. In L'Europa e la Comunità Internazionale Difronte alle Sfide dello Sviluppo. Available online: https://www.researchgate.net/publication/323153820_Empowering_Gender_Equality_through_Rural_Development_ Rural_Markets_and_Micro-Finance_in_Kyrgyzstan (accessed on 31 March 2021).

Gerlagh, Reyer, and Michiel A. Keyzer. 2001. Sustainability and the intergenerational distribution of natural resource entitlements. Journal of Public Economics 79: 315-41. [CrossRef]

Grasso, Marco. 2004. Climate Change: The Global Public Good. Working Paper Series No. 75. Milano: Department of Economics, Bicocca University of Milan.

Held, David, and Charles Roger. 2018. Three models of global climate governance: From Kyoto to Paris and beyond. Global Policy 9: 527-37. [CrossRef]

Howarth, Richard. B. 1998. An overlapping generations model of climate-economy interactions. Scandinavian Journal of Economics 100: 575-91. [CrossRef]

Introcaso, David. 2018. Climate Change Is the Greatest Threat to Human Health in History Health Affairs. Available online: https: / / www.healthaffairs.org/do/10.1377/hblog20181218.278288/full/ (accessed on 31 March 2021).

IPCC. 2018. Global Warming of 1.5 C. An IPCC Special Report on the Impacts of Global Warming of 1.5 C above Pre-Industrial Levels and Related Global Greenhouse Gas Emission Pathways, in the Context of Strengthening the Global Response to the Threat of Climate Change, Sustainable Development, and Efforts to Eradicate Poverty. Edited by Valerie Masson-Delmotte, Panmao Zhai, Hans O. Portner, Debra Roberts, James Skea, Priyadarshi R. Shukla, Anna Pira-ni, Wilfran Moufouma-Okia, C. Pean, Roz Pidcock and et al. Geneva: World Meteorological Organization.

Jenkins, Kirsten. 2018. Setting energy justice apart from the crowd: Lessons from environmental and climate justice. Energy Research $\mathcal{E}$ Social Science 39: 117-21.

John, Andrew, and Rowena Pecchenino. 1994. An overlapping generations model of growth and the environment. The Economic Journal 104: 1393-410. [CrossRef]

Judd, Kenneth L. 1998. Numerical Methods in Economics. Cambridge: MIT Press.

Kaul, Inge, Pedro Conceicao, Katell L. Goulven, and Ronald U. Mendoza. 2003. Providing Global Public Goods: Managing Globalization. New York: Oxford University Press.

Kelleher, David. 2000. Global Public Goods: International Cooperation in the 21st Century. New York: Oxford University Press. 
Koca, Deniz, Benjamin Smith, and Martin T. Sykes. 2006. Modelling regional climate change effects on potential natural ecosystems in Sweden. Climatic Change 78: 381-406. [CrossRef]

Kydland, Finn. E., and Edward C. Prescott. 1982. Time to build and aggregate fluctuations. Econometrica: Journal of the Econometric Society 50: 1345-370. [CrossRef]

Martens, Pim. 2013. Health and Climate Change: Modelling the Impacts of Global Warming and Ozone Depletion. London: Routledge.

McKinnon, Catriona. 2015. Climate justice in a carbon budget. Climatic Change 133: 375-84. [CrossRef]

Meadows, Donella. H., Dennis L. Meadows, Jorgen Randers, and William W. Behrens. 1972. The Limits to Growth. New York: Universe Books.

Mendicino, Caterina, and Andrea Pescatori. 2007. Credit Frictions, Housing Prices and Optimal Monetary Policy Rules. Available online: http:/ / repec.org/mmfc05/paper67.pdf (accessed on 31 March 2021).

Nardo, Michela, Michaela Saisana, Andrea Saltelli, and Stefano Tarantola. 2005. Tools for composite indicators building. European Comission 15: 19-20.

Nordhaus, William D. 1994. Managing the Global Commons: The Economics of Climate Change. Cambridge: MIT Press.

Nordhaus, William D. 2006. Paul Samuelson and global public goods. In Samuelsonian Economics and the Twenty-First Century. Oxford: Oxford University Press.

Ostrom, Elinor. 2010. Beyond Markets and States: Polycentric Governance of Complex Economic Systems. American Economic Review 100: 641-72. [CrossRef]

Ostrom, Elinor. 2012. Nested Externalities and Polycentric Institutions: Must We Wait for Global Solutions to Climate Change Before Taking Actions at Other Scales? Economic Theory 49: 353-69. [CrossRef]

Ostrom, Elinor. 2015. Governing the Commons. Cambridge: Cambridge University Press.

Panarello, Demetrio. 2021. Economic insecurity, conservatism, and the crisis of environmentalism: 30 years of evidence. Socio-Economic Planning Sciences 73: 100925. [CrossRef]

Picot, Helen, and Nicholas Moss. 2014. The Sustainable Development Goals: Will They Deliver Climate Compatible Development for Vulnerable Countries? Available online: https:/ / cdkn.org/resource/working-paper-the-sustainable-development-goals-willthey-deliver-climate-compatible-development-for-vulnerable-countries/?loclang=en_gb (accessed on 31 March 2021).

Punzo, Gennaro, Demetrio Panarello, Margherita M. Pagliuca, Rosalia Castellano, and Maria C. Aprile. 2019. Assessing the role of perceived values and felt responsibility on pro-environmental behaviours: A comparison across four EU countries. Environmental Science E Policy 101: 311-22.

Rhodes, Christopher J. 2016. The 2015 Paris climate change conference: COP21. Science Progress 99: 97-104. [CrossRef]

Roser, Dominic, Christian Huggel, Markus Ohndorf, and Ivo Wallimann-Helmer. 2015. Advancing the interdisciplinary dialogue on climate justice. Climatic Change 133: 349-59. [CrossRef]

Rutter, Otto. 2019. Power to the children. The Lancet Planetary Health 3: e102.

Sachs, Jeffrey D. 2014. Climate change and intergenerational well-being. In The Oxford Handbook of the Macroeconomics of Global Warming. New York: Oxford University Press, pp. 248-59.

Sadik-Zada, Elkhan R., and Andrea Gatto. 2020. The puzzle of greenhouse gas footprints of oil abundance. Socio-Economic Planning Sciences. [CrossRef]

Sadik-Zada, Elkhan R., and Andrea Gatto. 2021. Energy security pathways in South East Europe: Diversification of the natural gas supplies, energy transition, and energy futures. In From Economic to Energy Transition. Cham: Palgrave Macmillan, pp. $491-514$.

Schechter, Laura. 2007. Risk aversion and expected-utility theory: A calibration exercise. Journal of Risk and Uncertainty 35: 67-76. [CrossRef]

Schmitt-Grohe, Stephanie, and Martin Uribe. 2004. Solving Dynamic General Equilibrium Models. Using a Second-Order Approximation to the Policy Function. Journal of Economic Dynamics and Control 28: 755-75. [CrossRef]

Schneider, Maik. T., Christian P. Traeger, and Ralph Winkler. 2012. Trading off generations: Equity, discounting, and climate change. European Economic Review 56: 1621-44. [CrossRef]

Sen, Zekai. 2008. Solar Energy Fundamentals and Modeling Techniques: Atmosphere, Environment, Climate Change and Renewable Energy. London: Springer. Science \& Business Media, p. 276.

Shaffer, Gregory. 2012. International law and global public goods in a legal pluralist world. European Journal of International Law 23: 669-93. [CrossRef]

Shi, Lisi, and Richard. M. Suen. 2014. Asset bubbles in an overlapping generations model with endogenous labor supply. Economics Letters 123: 164-67. [CrossRef]

Shue, Henry. 2014. Climate Justice: Vulnerability and Protection. New York: Oxford University Press.

Smets, Frank, and Rafael Wouters. 2007. Shocks and frictions in US business cycles: A Bayesian DSGE approach. American Economic Review 97: 586-606. [CrossRef]

Sovacool, Benjamin. K. 2013. Adaptation: The complexity of climate justice. Nature Climate Change 3: 959. [CrossRef]

Stephan, Gunter, Georg Müller-Fürstenberger, and Pascal Previdoli. 1997. Overlapping generations or infinitely-lived agents: Intergenerational altruism and the economics of global warming. Environmental and Resource Economics 10: 27-40. [CrossRef]

Stern, Nicholas, and Chris Taylor. 2007. Climate change: Risk, Ethics, and the Stern review. Science 317: 203-04. [CrossRef]

UNESCO. 2014. Ethical Principles for Climate Change: Adaptation and Mitigation Report of COMEST. Oxford: John Wiley \& Sons Ltd. [CrossRef] 
United Nations (UN). 2015. Transforming our World: The 2030 Agenda for Sustainable Development. New York: Division for Sustainable Development Goals.

Weitzman, Martin L. 2009. On modeling and interpreting the economics of catastrophic climate change. The Review of Economics and Statistics 91: 1-19. [CrossRef]

Xu, Chong Y. 2000. Modelling the effects of climate change on water resources in central Sweden. Water Resources Management 14: 177-89. [CrossRef] 